\title{
Reconstruction of Brown's Tumor of the Mandible with Fibula Osteocutaneous Flap
}

\author{
Deepti Katrolia ${ }^{1}$ Dhritashree Mandal ${ }^{1} \quad$ Kaushal Priya Anand ${ }^{1} \quad$ Kamlesh Jharia $^{1} \quad$ Neelam Kumari ${ }^{1}$ \\ Collin Roy ${ }^{1}$
}

${ }^{1}$ Department of Plastic Surgery, NRS Medical College, Kolkata, West Bengal, India

Indian J Plast Surg 2019;52:254-255

Sir,

Hyperparathyroidism (HPT) was identified concurrently in Europe and United States in the mid-1920s. ${ }^{1}$

HPT is divided into primary, secondary, and tertiary categories. Primary HPT occurs in the setting of excessive parathyroid hormone (PTH) secretion by an autonomous gland resulting in hypercalcemia.

Brown's tumor is a metabolic bone disease that develops in primary, secondary, or tertiary HPT.

Our patient, 16-year-old female, was apparently alright one and a half years back when she presented with complaints of hard swelling arising from the mandible which was gradually increasing in size associated with the generalized body ache.

The patient was investigated and her PTH was $1,900 \mathrm{pg} / \mathrm{mL}$ (normal: $12-65 \mathrm{pg} / \mathrm{mL}$ ), alkaline phosphatase was 2,389 IU/L (normal: 47-119 IU/L), calcium $11.5 \mathrm{mg} / \mathrm{dL}$ (normal: $8.5-10.5 \mathrm{mg} / \mathrm{dL}$ ), and phosphate 2.5 (normal: $2.5-4.5 \mathrm{mg} / \mathrm{dL}$ ).

The parathyroid scan using $99 \mathrm{~m}$ Technetium scan sestamibi manifested tracer retention near the lower pole of the right lobe of thyroid and increased tracer uptake involving the mandibular region.

The patient then underwent right hemithyroidectomy with excision of the right superior and inferior parathyroid glands. Postoperatively serum calcium was $6.9 \mathrm{mg} / \mathrm{dL}$, and tablet calcium carbonate $500 \mathrm{mg}$ was administered twice daily and vitamin D3 60,000 IU was started once a week. The histopatholgy examination revealed parathyroid adenoma.

The patient had multiple bony lesions of the mandible extending from the right premolar to the left incisor which was hard in consistency with no occlusal deformity ( - Figs. 1 and 2).

The patient was observed for a duration of 6 months postparathyroidectomy for the regression of mandibular growth, but when symptoms did not abate, we did wide resection of the mandible followed by reconstruction with

Address for correspondence Deepti Katrolia, MCh, Department of Plastic Surgery, All India Institute of Medical Sciences, Room no 403, OPD Building, 4th floor, Jodhpur, Rajasthan 342005, India (e-mail: deepti.katrolia@yahoo.com).

an osteocutaneous free fibula flap ( - Fig. 3). Flap vascularity was good ( - Fig. 4 ). The patient was given oral calcium supplements.

Nine cases have been reported from India till now, which were treated with parathyroidectomy, curettage of the tumor, or medical management with steroids except for the case reported by Praveen et $\mathrm{al}^{2}$ where excision with a reconstruction plate was done.

In our case, we planned reconstruction of the segmental loss of the mandible with the free fibula osteocutaneous flap.

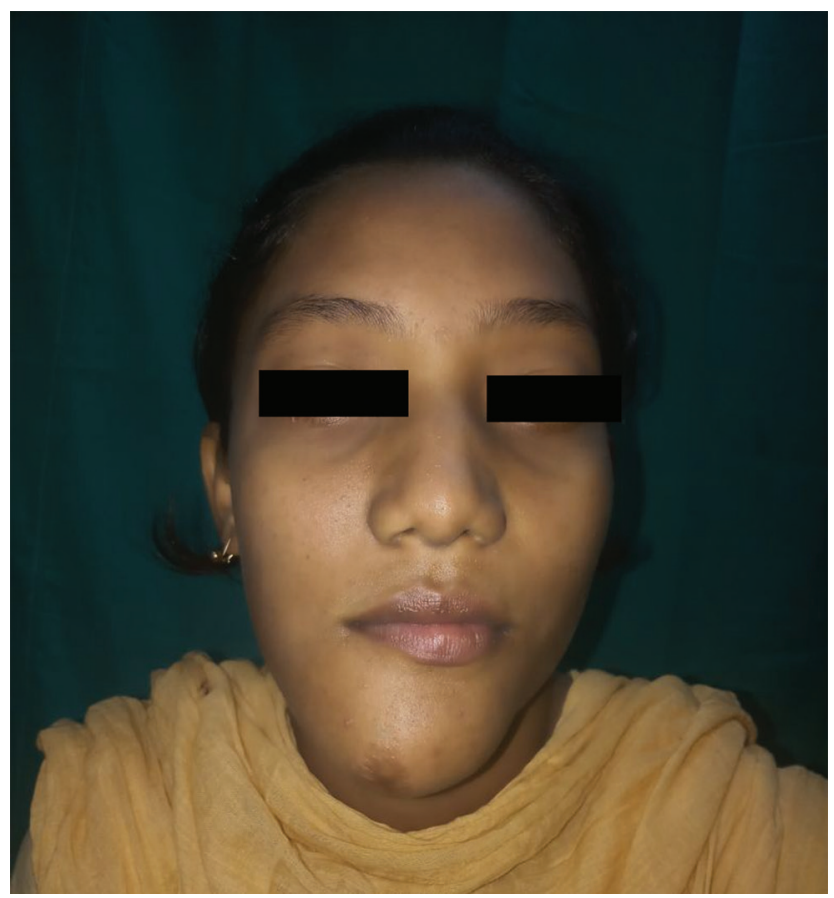

Fig. 1 Preoperative anteroposterior view showing mandibular lesion at the right side of the mandible.

DOI https://doi.org/

10.1055/s-0039-1696789

ISSN 0970-0358.
License terms

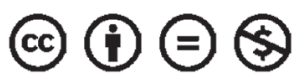




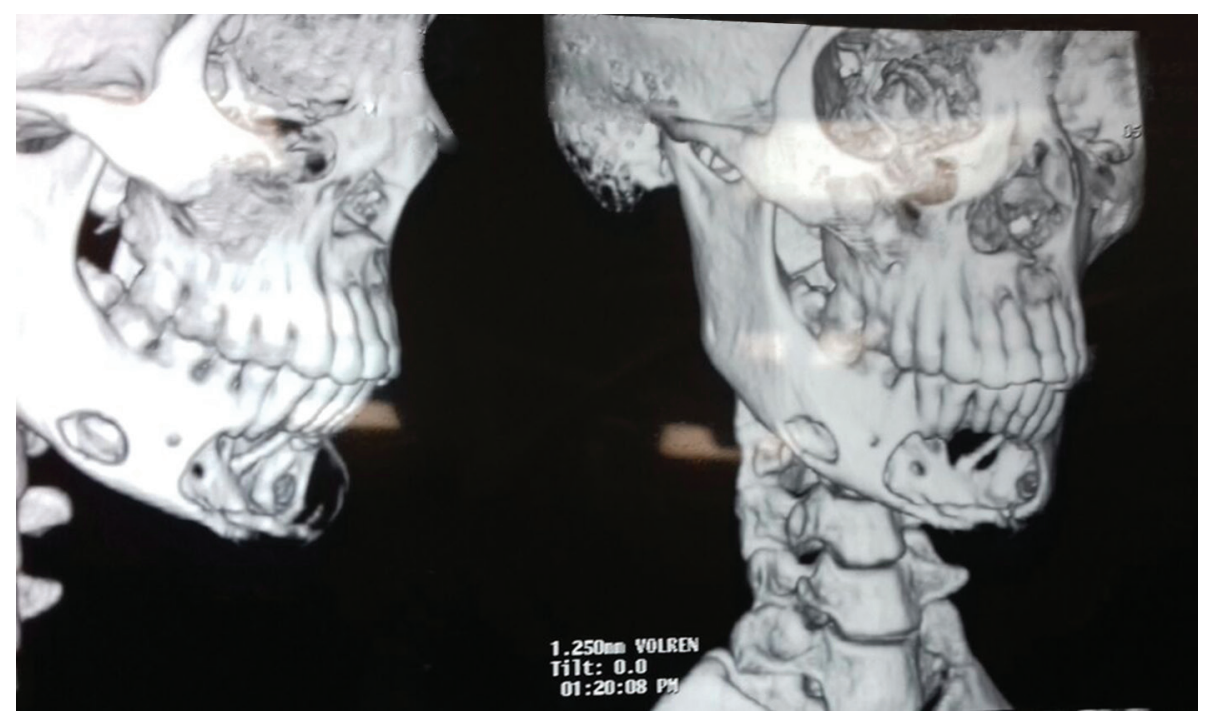

Fig. 2 CECT face showing lesion extending from right premolar to left incisor along with skip lesion. CECT, contrast-enhanced computed tomography.

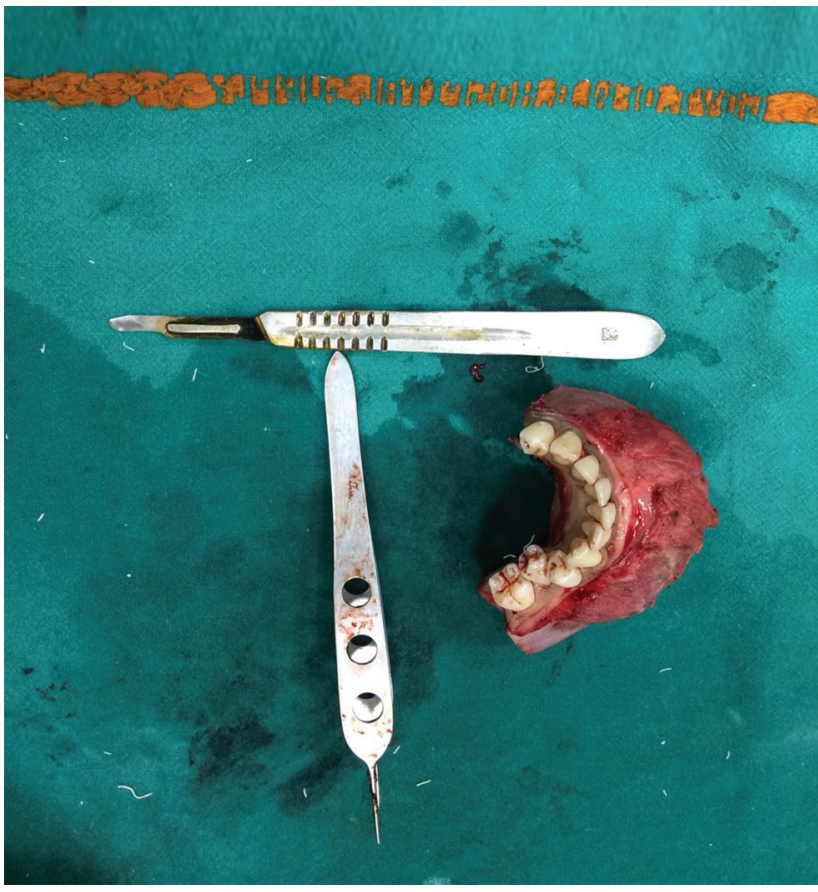

Fig. 3 Intraoperative picture showing excised specimen.

The patient is considered for dental rehabilitation is planned at a later date.

\section{Financial Support}

Nil.

\section{Conflict of Interest}

None.

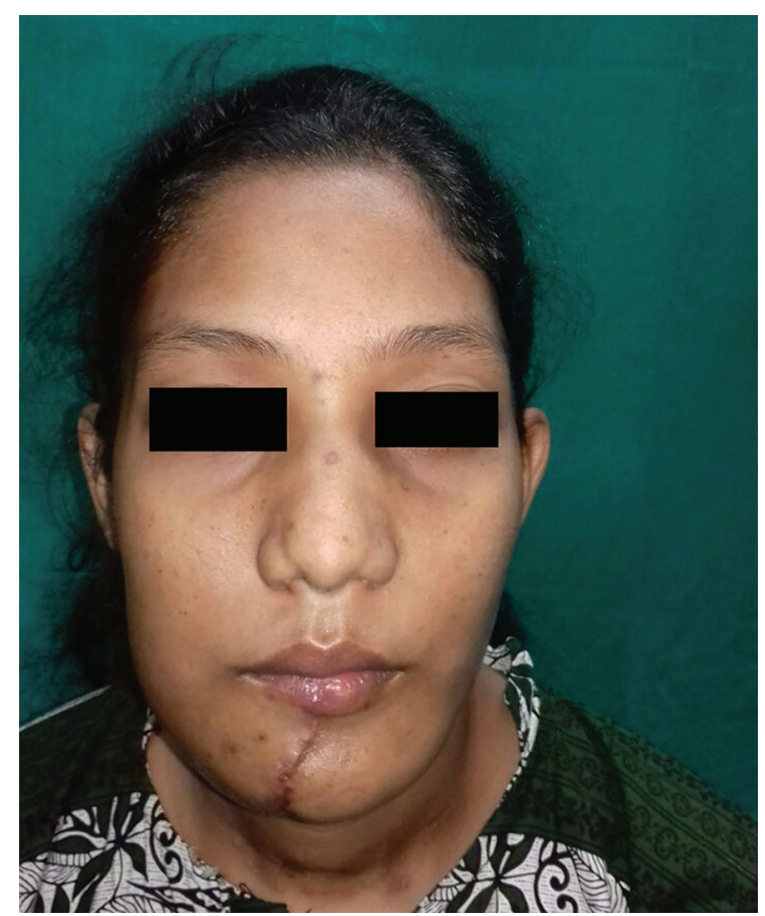

Fig. 4 Post operative anteroposteior view at 3 months follow-up.

\section{References}

1 Cope O. The study of hyperparathyroidism at the Massachusetts General Hospital. N Engl J Med 1966;274(21):1174-1182

2 Praveen AH, Thriveni R. Maxillary and mandibular hyperparathyroidism. Natl J MaxillofacSurg 2012;3(1):51-54 